\title{
Review on Zoonotic Importance of Bovine Tuberculosis and Its Control
}

\author{
Adem Mume Jemal \\ School of Veterinary Medicine, College of Agriculture and Veterinary Medicine, Jimma University, \\ Jimma, Ethiopia \\ Email: jemaladem123@gmail.com
}

Received 2 March 2016; accepted 19 March 2016; published 23 March 2016

Copyright (C) 2016 by author and OALib.

This work is licensed under the Creative Commons Attribution International License (CC BY). http://creativecommons.org/licenses/by/4.0/

\section{(c) (i) Open Access}

\begin{abstract}
Bovine tuberculosis is a chronic infectious zoonotic disease of domestic animals and humans. It is characterized by formation of granulomas in tissue especially the lungs, lymph nodes, liver, intestines and the kidneys. Mycobacterium bovis is the main etiological agent of BTB (Bovine tuberculosis) which is an acid fast staining bacterium due to waxy substance (mycolic acid) present in its bacterial cell wall. The bacteria can be transmitted by both aerogenous and enterogenous routes. In Ethiopia bovine tuberculosis is endemic and mostly transmitted to humans through ingestion of unpasteurized contaminated milk and contact with infected animals. Disease causes development of miliary tubercular lesions, chronic cough, obstructions of air passages and alimentary tract or blood vessels and enlargement of lymph nodes. A spectrum of Cell-Mediated Immune responses (CMI) predominate infection, projecting the role of macrophages and T-cell populations. In advanced stage, there is increased humoral response. Tuberculinization test, single intradermal test and comparative intradermal test, is the valuable delayed type hyper sensitivity test used for diagnosing TB in live animal, and used in TB eradication and for international trade. Vaccination of calves with attenuated bovine-strain of tuberculosis bacterium, known as Bacillus of Calmette and Guerin (BCG) and testing and culling are important measure in BTB control and prevention endemic area like Ethiopia. It is important to pasteurize milk before human consumption to reduce public health risk.
\end{abstract}

\section{Keywords}

Mycobacterium Bovis, Bovine, Zoonotic Disease, Control

Subject Areas: Infectious Diseases

\section{Introduction}

Tuberculosis is an important bacterial disease in humans and animals worldwide. It infects over 2 billion people

How to cite this paper: Jemal, A.M. (2016) Review on Zoonotic Importance of Bovine Tuberculosis and Its Control. Open Access Library Journal, 3: e2504. http://dx.doi.org/10.4236/oalib.1102504 
or one third of the world's population and it is also estimated that 1.5 to 2million people die from tuberculosis each year [1]. A total of $95 \%$ of cases occur in humans in developing countries. Worldwide it is said to be the leading cause of death by infectious disease [2]. Tuberculosis (TB) is a complex and multi-species disease which can be of three types, bovine, avian and human TB [3].

M. bovis is a member of Mycobacterium Tuberculosis Complex (MTC) and based upon 16S ribosomal RNA sequence studies it shared more than 99.95\% identity with other members of MTB complex [4] [5]. Bovine tuberculosis (BTB) is the zoonotic disease transmitted from animal to human and makes a significant economic impact due to high cost of eradication programs and has serious consequences for movements of animals and their products, biodiversity, public health and significant economic effect [5] [6]. World Health Organization (WHO) classified bovine tuberculosis among seven neglected zoonontic diseases having potential to infect man [7].

In countries with tuberculosis eradication programmes, clinical evidence of tuberculosis in cattle is seldom encountered because the intradermal tuberculin test enables presumptive diagnosis and elimination of infected animals before signs appear. The thorough application of tuberculin testing and culling of reactor cattle has eliminated $M$. bovis infection from farmed bovine populations in some countries, but this strategy has not been universally successful. Extensive investigations of sporadic $M$. bovis reoccurrence have shown that wildlife reservoirs exist in some countries and can act as a source of infection for cattle, deer and other livestock. The risk that these reservoirs of infection constitute for domestic animals and humans is quite variable depending on the specific epidemiological situation for the species and the environment [8].

Among different tests used to diagnose tuberculosis, intradermal test is the most common test for the diagnosis in the live animal on the basis of delayed hypersensitivity reaction to bovine tuberculin. The test must be carried out on the side of the neck. To obtain results that are valid, the hair should be clipped around the injection site, there should be accurate intradermal injection of the tuberculin and careful pre- and post-inoculation skin thickness measurement should be made using calipers [9]. The present review addresses zoonotic importance of bovine tuberculosis (BTB), a chronic multi-species disease, the etiological agent, its diagnosis, prevention and control, and treatment options and the public health significance of this important disease.

\section{Literature Review}

\subsection{Etiology}

Genus mycobacterium is characterized phenotypically as non-motile, noncapsular, non-spore forming, obligate aerobic, thin rod usually straight or slightly curved having $1-10 \mu \mathrm{m}$ length and $0.2-0.6 \mu \mathrm{m}$ width, facultative intracellular microbe and has a slow generation time about 15 - 20 hours. Its cell wall is rich in lipids (mycolic acid) that provide it the thick waxy coat which is responsible for acid fastness and hydrophobicity. This waxy coat (mycolic acid) is also greatly contributing for the bacterium resistance to many disinfectants, common laboratory stains, antibiotics and physical injuries. It probably also contributes to the slow growth rate of some species by restricting the uptake of nutrients [10].

Mycobacterium bovis is the main etiological agent of bovine tuberculosis. It is found that $M$. bovis best survive in frozen tissue and there is adverse effects of tissue preservative i.e. sodium tetraborate on viability [11]. In the environment $M$. bovis can survive for various months especially in cold as well as dark and conditions which is moist. The survival period varies from $18-332$ days at $12^{\circ} \mathrm{C}-24^{\circ} \mathrm{C}\left(54^{\circ} \mathrm{F}-75^{\circ} \mathrm{F}\right)$ which is dependent of sunlight exposure. From soil or grazing pasture there is infrequent isolation of this organism. It has been found that culture of the organism can be done for approximately two years in samples that are stored artificially. The viability of the organism has been found more recently to be between 4 - 8 weeks in $80 \%$ shade whereas it can get destroyed in either summer or winter on New Zealand pastures [10] [11]. The incubation period of M. bovis is 3 weeks [11].

\subsection{Epidemiology}

Tuberculosis (TB) is chronic disease in nature affecting a wide range of mammals that include: humans and cattle, deer, llamas and other wild animals. All species including humans with various age groups are susceptible. The bacteria primarily affect the cattle and other domestic and wild animals as well as human being. Disease is found throughout the world but more prevalent in Africa, parts of Asia and America. The prevalence of disease 
is high in the tropical and sub-tropical countries [11]. The prevalence of bovine tuberculosis in smallholder dairy farms was $6.9 \%$, in traditionally managed extensive production system was $12.9 \%$ and in intensive dairy farms 24.6\% based on comparative tuberculin skin test in different areas in Ethiopia [12].

Bovine TB is distributed globally except Antarctica and those countries such as Caribbean islands, parts of South America and Australia where it has been eradicated by following strict test and slaughter policies. It is major health problem in India. Chances and severity of infection depend upon several predisposing factors like environmental variables, topographic causes, anthropogenic variables, seasonality, immunosuppression, long antibiotic therapy, working conditions and environmental factors. Infected cattle are the main source of infection for other cattle. Organisms are excreted in exhaled air, sputum, faeces, milk, urine, vaginal and uterine discharges and discharges from open peripheral lymph nodes [11] [13].

Epidemiology of bovine TB is influenced from many risk factors as genetic, behavioral, biological or environmental which have effect on transmission, establishment of infection and expression of disease [14]. Male badgers are more affected as compare to female. Male have higher risk of mortality which promote gender influence while risking transmission of TB to cattle [15]. It is more prevalent in dairy workers exposed to poor control areas of bovine tuberculosis. The pulmonary form of disease is more developed in occupational groups working with animals infected from $M$. bovis on farm or slaughter house, than the alimentary form of disease. Bovine tuberculosis herd prevalence was positively related with Mycobacterium Tuberculosis Complex (MTC) and also correlated positively with size of island, number of imported cattle and presence of wild host but not with isolation of cattle as well as density of cattle. Incidence of TB in cattle progeny is also affected by hereditary and maternal influences [11]. The factors associated with tuberculosis which influence the occurrence of disease are sex, breed and social management of livelihood conditions [16] [17].

\subsection{Sources of Infection and Ways of Transmission}

Bovine Tuberculosis can be transmitted in various ways. For instance in air that is exhaled; sputum and urine, feces as well as pus the bacteria can spread. Either direct contact or contact with infected animal excreta, aerosol inhalation can spread the disease that depends on the involvement of the species [18].

The common mode of transmission is inhalation or ingestion. Aerogenous or inhalation: it is mainly by droplet infection, inhalation of dust contaminated by sputum, faeces, urine of infected animals. Thus close housing and overcrowding along with improper management predisposes to the disease. Zebu (Brahman) type cattle are thought to be much more resistant to tuberculosis than European cattle. The dynamics of $M$. bovis transmission from an effective disseminator tuberculous animal to susceptible hosts are currently not clearly identified and are meagerly understood. Though, infection is principally confined to the respiratory system as bacteria aim to establish the infection within the lung. Infected cattle are considered as possible source of infection as they shed significant amount of $M$. bovis through droplet nuclei in to the environmental and may act as source of intraherd transmission [19] [20].

Primarily, tuberculosis is a respiratory disease and is transmitted through mainly by air born route within and between species during close contact [11]. In case of enterogenous route or ingestion through buccal mucosa, pharyngeal mucosa and intestinal mucosa the organism may enter into the animal body. It is also through the congenital route but is less common mode of acquiring infection [21]. The infected bull may also transmit disease or through artificial insemination with the use of infected semen [11]. The $M$. bovis is transmitted from animal to man through ingestion of unpasteurized dairy product, milk of infected cattle and undercooked meat which was recognised as a major public health problem [11].

\subsection{Clinical Signs}

Basic pathogenic mechanisms are more or less same in case of human TB and bovine tuberculosis. Developing technologies support the fact of identical pathogenesis, because of unusually high conserved sequence similarity in genome of TB causing bacteria in more than 99.95\% animals [22] [23].

TB is a chronic debilitating disease occurs in cattle. No symptoms occur in early stage of disease that is asymptomatic. However, in late stage, there is progressive emaciation, a mild fluctuating fever, weakness and in-appetence. When infection is present in the lung then dyspnoea, moist cough or trachypnoea may occur. In the terminal stage, animal become extremely emaciated and develop acute respiratory distress. Involvement of respiratory tract and its role in pathogenesis of disease is evidenced by the predominant distribution of lesions 
present in upper respiratory tract, lung and tonsils in affected human as well as in animals. Some cows with extensive miliary tubercular lesions are clinically normal but in most cases progressive emaciation unassociated with other clinical signs occur, inspite of good appetite. A capricious appetite and fluctuating temperature are commonly associated with disease. The hair coat may be rough. Affected animal tend to become more docile and sluggish but eyes remain bright and alert. These general signs often become more pronounced after calving. Pulmonary involvement is characterized by chronic cough due to bronchopneumonia. Cough occurs only once or twice at a time and is low suppressed and moist which is easily stimulated by squeezing the pharynx or by exercise and is most common in morning and in cold weather [19].

In advanced cases, air passages, alimentary tract, or blood vessels may be obstructed by enlargement of lymphnodes. Lymph nodes of the head and neck may become visibly affected and sometimes rupture and drain. Involvement of the digestive tract is manifested by intermittent diarrhoea and constipation in some instances. There may be chances of bloat occur due to pressure of enlarged mediastinal glands on the oesophagus. The enlargement of retropharyngeal glands results in dysphagia. Extreme emaciation and acute respiratory distress may occur during the terminal stages of tuberculosis. Lesions on the female genitalia may occur, while male genitalia are seldom involved. Tuberculosis mastitis is of major importance because of danger to public health and of spread of disease to claves and difficulty of differentiating it from other forms of mastitis [21]. Experiments have shown that lions may also become susceptible to bovine TB [24].

With the help of descriptive statistic and regression model on data analysis, indicates that tuberculosis lesion are mostly occur in lung and lymph node of respiratory system. Disease usually has a prolonged course, and symptoms take months or years to appear. The usual clinical signs include: Weakness, loss of appetite, weightloss, fluctuating fever, intermittent hacking cough, diarrhoea, large prominent lymph nodes, anorexia, and indurations of udder [16].

It is usually a chronic debilitating disease incattle, but it can occasionally be acute and rapidly progressive. Early infections are often asymptomatic. In countries with eradication programs, most infected cattle are identified early and symptomatic infections are uncommon. In late stages, commonsymptoms included progressive emaciation allows grade fluctuating fever, weakness and in appetence. Animals with pulmonary involvement usually has cough that is worse in the morning, during cold weather of exercise and may have dyspnea ortachypnea. In terminal stage, animals may become extremely emaciated and develop respiratory distress. In the final stage of the disease, animals become disoriented, can't climb, and may be seen wandering about in day light [25].

\subsection{Pathogenesis}

Once bacteria entered through aerosolized droplets or ingestion it is established in a herd of cattle. The incubation period can range from months to years with the severity depending on the immune system of each individual animal. The bacteria usually enter the respiratory system of a cow and settle in the lungs. Macrophages in lungs are then responsible for phagocytizing the organism. The organism replicates intracellularly after it has been taken up by the macrophages. A granuloma or tubercle forms as the body tries to wall off the infected macrophages with fibrous tissue. The granuloma is usually $1-3 \mathrm{~cm}$ in diameter, yellow or gray, round and firm. On cut section, the core of the granuloma consists of dry yellow, caseous, or necrotic cellular debris. The infection can spread hematogenously to lymph nodes and other areas of the body and cause smaller, 2 - $3 \mathrm{~mm}$ in diameter, tubercles. The formation of these smaller tubercles is known as "miliary tuberculosis". The histological lesions consist of necrotic cells in the center of the tubercle surrounded by epitheloid cells and multinucleated giant cells all encapsulated by collagenous connective tissue. The necrotic core of cells can often become calcified as the tubercle matures [9].

\subsection{Postmortem Lesions}

It is characterized by the formation of granulomas (tubercles) where bacteria have localized. These granulomas are usually yellowish and eithercaseous, or calcified, they are often encapsulated. In some species such as deer, the lesion tends to resemble abscesses rather than typical tubercles. Some tubercles are small enough to be missed by the naked eye unless the tissue is sectioned. In cattle, tubercles are found in the lymph nodes, particularly those of the head and thorax. It is common in the lungs, spleen, liver and the surfaces of body cavities [13].

In disseminated case, lesions are sometimes founds on the female genitalia, but are rare on the male genitalia. 
In countries with good control programs, infected cattle typically have few lesions at necropsy. Most of those lesions found in lymph nodes associated with the respiratory system. However, small lesions can often be discovered in the lungs of these animals if the tissues are sectioned [11] [13].

\subsection{Diagnosis}

Although the presumptive diagnosis of TB is often based on clinical suspicion and radiological data, a definitive diagnosis of the disease requires microbiological assays. Laboratory diagnosis of TB has been based on smear microscopy, culture and phenotypic identification. While the quickest, easiest and cheapest method available is acid-fast staining, its low sensitivity ( $45 \%-80 \%$ of positive cultures) has limited its usefulness, especially in geographical areas of lower incidence, in BTB [10].

\subsubsection{Acid-Fast Staining}

It is used to detect acid fast bacilli (AFB) in clinical specimens by Ziehl-Neelsen (ZN) or fluorescent staining. It is a cost-effective tool for diagnosing of BTB and to monitor the progress of treatment especially in developing countries [10].

The cell walls of these acid-fast bacteria contain approximately equal amounts of polysaccharide. The high lipid content, which ranges from $20 \%-40 \%$ of the dry cell weight, is largely responsible for the ability of these bacteria to resist decolorization with acidified organic solvents. The bacteria that take up this stain, including $M$. bovis, will appear as short red or pink rods when examined under a microscope [26]. Preliminary examination of tissues suspected of being TB should include the preparation of suitably stained smears. The identifiable smear can be made on a new slide from scrapings of the cut surface of tissue. The smear should be air dried and fixed by flaming for one to two seconds. The smears are treated as with concentrated carbolfuchsin by heating and then decolorized with a sulfuric acid and alcohol solution. Malachite green or methylene blue is commonly used counter stains [10]. The stained slides are observed with an ordinary light microscope for the presence of acidfast an ordinary light microscope for the presence of acid-fast bacilli, which appear as red, colloidal or bacillary cells 1 - 3 microns in length occurring singly or in clumps [27].

\subsubsection{Culturing}

In the isolation of mycobacterium can be done by culturing on the egg-based media known as Lowenstein-Jensen (LJ) medium. The luxuriant growth of $M$. tuberculosis on glycerol containing media, giving the characteristic 'rough, tough and buff' colonies is known as eugenic while the growth of M. avium on media containing glycerol is also described as eugenic whereas $M$. bovis has sparse, thin growth on glycerol containing media that is called dysgenic, however, grows well on pyruvate-containing media without glycerol [28].

\subsubsection{Tuberculin Test}

The standard method for detection of bovine tuberculosis is the tuberculin test (the prescribed test for international trade), which involves the intradermal injection of bovine tuberculin purified protein derivative (PPD) and the subsequent detection of swelling (delayed hypersensitivity) at the site of injection 72 hours later. This may be performed using bovine tuberculin alone or as a comparative test using avian and bovine tuberculins. The tuberculin test is usually performed on the mid-neck, but the test can also be performed in the caudal fold of the tail. The skin of the neck is more sensitive to tuberculin than the skin of the caudal fold. To compensate for this difference, higher doses of tuberculin may be used in the caudal fold [9].

Delayed hypersensitivity may not develop for a period of 3 - 6 weeks following infection. Thus, if aherd/ animal is suspected to have been in contact very recently with infected animals, delaying testing should be considered in order to reduce the probability of false-negatives. As the sensitivity of the test is less than $100 \%$, it is unlikely that eradication of tuberculosis from a herd will be achieved with only a single tuberculin test. It should be recognized that when used in chronically infected animals with severe pathology, the tuberculin test may be unresponsive. The tuberculin test has not been well validated in most non-bovid and non-cervid species [9].

The comparative intradermal tuberculin test is used to differentiate between animals infected with $M$. bovis and those responding to bovine tuberculin as a result of exposure to other mycobacteria. This sensitization can be attributed to the antigenic cross-reactivity among mycobacterial species and related genera. The test involves the intradermal injection of bovine tuberculin and avian tuberculin into different sites, usually on the same side 
of the neck, and measuring the response 3 days later [9] [29].

The potency of tuberculins must be estimated by biological methods, based on comparison with standard tuberculins, and potency is expressed in International Units (IU). In several countries, bovine tuberculin is considered to be of acceptable potency if its estimated potency guarantees per bovine dose at least $2000 \mathrm{IU}( \pm 25 \%)$ in cattle. In cattle with diminished allergic sensitivity, a higher dose of bovine tuberculin is needed, and in national eradication campaigns, doses of up to $5000 \mathrm{IU}$ are recommended. The volume of each injection dose must not exceed $0.2 \mathrm{ml}$ [9].

According to OIE [9], the procedures for tuberculin test are listed as the following:

i) The injection sites must be clipped and cleaned. A fold of skin within each clipped area is measured with callipers and the site marked prior to injection. The correct injection of tuberculin, and dose must be no lower than 2000 International Units (IU) of bovine or avian tuberculin. The distance between the two injections should be approximately $12-15 \mathrm{~cm}$. In young animals in which there is no room to separate the sites sufficiently on one side of the neck, one injection must be made on each side of the neck at identical sites in the centre of the middle third of the neck. The skin-fold thickness of each injection site is re-measured 72 hours after injection. The same person should measure the skin before the injection and when the test is read.

ii) The interpretation is based on observation and the recorded increases in skin-fold thickness. In the single intradermal test (which requires a single injection of bovine tuberculin), the reaction is commonly considered to be negative if only limited swelling is observed, with an increase of no more than $2 \mathrm{~mm}$ and without clinical signs, such as diffuse or extensive oedema, exudation, necrosis, pain or inflammation of the lymphatic ducts in that region or of the lymph nodes. The reaction is considered to be inconclusive if none of these clinical signs is observed and if the increase in skin-fold thickness is more than $2 \mathrm{~mm}$ and less than $4 \mathrm{~mm}$. The reaction is considered to be positive if clinical signs, as mentioned above, are observed or if there is an increase of $4 \mathrm{~mm}$ or more in skin-fold thickness.

Moreover, in M. bovis-infected herds, any palpable or visible swelling should be considered to be positive. Sometimes a more stringent interpretation is used, particularly in a high risk population or incontact animals. Animals that are inconclusive by the single intradermal test should be subjected to another test after an interval of 42 days to allow desensitization to wane (in some areas 60 days for cattle and 120 days for deer are used). Animals that are not negative to this second test should be deemed to be positive to the test. Animals that are positive to the single intradermal test may be subjected to a comparative intradermal test or blood test.

iii) In the interpretation of the intradermal comparative test, a reaction is usually considered to be positive if the increase in skin thickness at the bovine site of injection is more than $4 \mathrm{~mm}$ greater than the reaction shown at the site of the avian injection. The reaction is considered to be inconclusive if the increase in skin thickness at the bovine site of injection is from 1 to $4 \mathrm{~mm}$ greater than the avian reaction. The reaction is considered to be negative if the increase in skin thickness at the bovine site of injection is less than or equal to the increase in the skin reaction atthe avian site of injection.

\subsubsection{Enzyme-Linked Immunosorbent Assay (ELISA)}

The ELISA appears to be the most suitable of the antibody-detection tests and can be a complement, rather than an alternative, to tests based on cellular immunity. It may be helpful in anergic cattle and deer. An advantage of the ELISA is its simplicity, but sensitivity is limited mostly because of the late and irregular development of the humoral immune response in cattle during the course of the disease. Specificity is also poor in cattle when complex antigens such as tuberculin or $M$. bovis culture filtrates are used. However, a comparison of antibody levels to PPD-B and PPD-A has been shown to be useful in increasing specificity in the ELISA [9] [30].

Improvement may be possible by using a combination of different antigens, including proteins. Moreover, in $M$. bovis infected animals, an anamestic rise has been described, resulting in better ELISA results 2 - 8 weeks after a routine tuberculin skin test [31]. The ELISA may also be useful for detecting $M$. bovis infections in wildlife. However, its sensitivity in cattle is relatively low. This test is now licensed in the USA by the USDA for species such as elephants and nonhuman primates and is approved for use in the United Kingdom for badgers [9] [13].

\subsubsection{Nucleic Acid Recognition Methods}

PCR has been widely used for the detection of $M$. tuberculosis complex in clinical samples (mainly sputum) in 
human cases and has recently been used for the diagnosis of tuberculosis in animals. The real time PCR determine the status of infection in cattle for bovine tuberculosis as compare to the IFN gamma mRNA in blood culture. Another useful diagnostic method for bovine tuberculosis in cattle is RT-PCR [32].

Bacterial culture and post-mortem confirmation of tuberculosis is insufficiently sensitive. So, veterinarians and other health researchers have evaluated other diagnostic approach i.e. immunological including lateral-flow devices and Enzyme-linked Immunosorbent Assay (ELISA), tuberculin skin test and interferon-gamma release assay [30].

\subsection{Treatment}

In human tuberculosis, drugs like isoniazid, combinations of streptomycin and para-aminosalicylic and other acids are commonly used. The treatment of animals with tuberculosis is not a favored option in eradicationconscious countries and is not economical. Long term therapy requirement of the disease can create the chances of development of multidrug resistant (MDR), extremely drug resistant (XDR) and even totally drug resistant (TDR) bacterial strains if treatment regime is not properly followed. So that vaccination of calves with BCG and testing and culling is important for prevention and eradication of tuberculosis [11].

Bacillus Calmette and Guérin (BCG) vaccine is the only TB vaccine licensed for use in humans and has advantages for use in cattle since the vaccine is safe, inexpensive, is commercially produced for human application. BCG vaccine has variable levels of protection efficacy in humans against pulmonary TB in children and adults, ranging from $0 \%-80 \%$ [33].

However, in animals vaccination with BCG sensitises animals to the tuberculin skin test, and vaccinated animals will therefore, at least for a significant period postvaccination, become test positive in the classical skin test. For this reason, test and slaughter-based control strategies based on tuberculin skin testing were favoured above BCG vaccination in many countries including Ethiopia [34].

Currently in Ethiopia, the incidence of MDR-TB strains is a continuing challenge to the TB control program of human tuberculosis. The study conducted on northwest Ethiopia showed a higher rate at 5\% of MDR-TB patients [35], and the other studies in other parts of the country indicated 1.3\% and 6.5\% of MDR-TB [36] [37] and Hirpa et al. [38] reported 32.8\% and 134 MDR-TB cases, respectively. In addition, it is reported that overall prevalence of MDR-TB of 5.7\% among all cases, with the prevalence of MDR-TB among previously treated cases being $13.9 \%$ and among new cases only $2.3 \%$ [39].

Most commonly the history of previous treatment was found to be a risk factor for being infected by MDRTB strain. Therefore, maximizing early case detection and treatment, strengthening TB infection control activities and proper implementation of directly observed therapy, short course (DOTS) are recommended to reduce the burden of MDR-TB [39].

In human medicine, the treatment policy for MDR-TB (resistant to both isoniazid and rifampin) in Ethiopia combines standardized and individualized treatment based on second-line drug susceptibility testing [40]. The most drug regimens currently used to treat MDR-TB include an aminoglycoside (e.g., streptomycin, kanamycin, amikacin) or capreomycin, and a fluoroquinolone [41]. These patients should be managed by or in consultation with physicians experienced in the management of MDR-TB. A standard regimen is given to all MDR-confirmed cases daily under direct observation by a health care worker at a health care centre and by family DOTS supporter (s) at home [40] [41]. Furthermore, continuous monitoring and building capacity for family DOTS supporters are essential components of the DOTS strategy. The regimens include at least four drugs that are certain or expected to be effective and the duration is a minimum of 18 months after culture conversion [41]. The purpose of effective treatment of drug susceptible TB is curing the patient, interrupting transmission of TB to other persons, and preventing the development of drug resistant strains [42]. These goals are not being achieved in many regions of the country though anti-tuberculosis drugs are available. This might be due to either patient non-adherence to treatment or clinicians' non-adherence to the national treatment guidelines or both [43].

\subsection{Economic Importance}

Tuberculosis occurs in almost every country of the world and is of major importance in dairy cattle due to high morbidity and loss of production as infected animals lose 10\% - 25\% of their productive efficiency. Apart from these, advance tuberculosis may lead to death of the animals. WHO declared tuberculosis as global emergency 
[11]. About one third of human populations of the world are suffering from tuberculosis infection [44]. Tuberculosis has great importance regarding the economy of the livestock industry because it can infect the human population due to its zoonotic nature; therefore it is an important public health issue [45]. It is listed disease by World Organisation for Animal Health formerly Office International des Epizootics (OIE). Tuberculosis also has significance to the international trade of animals and animal product [46].

\subsection{Public Health Risks}

Human tuberculosis due to $M$. bovis is usually underestimated or under diagnosed because of no clinical, radiographical and histopathological differentiation of tuberculosis caused by M. tuberculosis and M. bovis [47]. M. bovis is not the major cause of human tuberculosis but it can infect human beings too either by consuming raw milk, meat and their products from infected animals [48], or by inhaling infective droplets or direct exposure to infected animals [11]. In an estimate, about $10 \%$ cases of human tuberculosis are caused by $M$. bovis, while majority are caused by M. tuberculosis [47]. In countries wherein milk is pasteurized and there is effective implementation of bovine tuberculosis program, tuberculosis in human due to $M$. bovis is very rare. But in areas where the disease in bovine is poorly controlled the reporting of the disease is more frequently done. In farmers as well as abattoir workers and others the incidence rate is higher. Exposure to other species apart from cattle can cause infection in human. It has been documented that goats as well as seals, farmed elk and rhinoceros can also act as sources of bovine tuberculosis. A source of infection may be wildlife especially in countries where people use to take bush meat [49] [50]. If the whole carcass is condemned then it indicates a high degree of tuberculosis infection and its transmission so it requires immediate attention from both the economic and public health point of view [51] [52]. Being cause of chronic granulomatous disease tubercle bacilli increases susceptibility to bladder and lung cancer. Though BCG induced cytotoxicity of bladder has paved the way towards initiation of BCG immunotherapy for treatment of bladder cancer [53] [54].

\subsection{Control and Prevention}

Tuberculosis needs to be prevented and controlled because it causes loss of productivity in animals infected; there is risk of infection to humans [29]. However, because of financial constraints, scarcity of trained professionals, lack of political will, as well as the underestimation of the importance of zoonotic tuberculosis in both the animal and public health sectors by national governments and donor agencies, control measures are not applied or are applied inadequately in most developing countries [55]. Standard public health measures used to manage patients with contagious M. tuberculosis should be applied to contagious patients with M. bovisto stop person-person transmission [56]. Cattle should not be treated at all and as such farm animals with tuberculosis must be slaughtered (culled). This is due to the fact that $M$. bovis is resistant to pyrazinamide, which is widely used in the treatment of infections caused by M. tuberculosis Complex in humans [57].

In developed countries, regular testing and removal of infected animals under mandatory national bovine tuberculosis programs have successfully carried out to control and eradication of bovine tuberculosis, the program have been successful in many European union member states and in seven central European countries between 1953 and 1980 [58]. In order to reduce the risk associated with consumption of contaminated milk and meat, it is necessary that specific hygiene rules for food of animal origin be laid down to prevent infected animals from entering the food chain. Meat inspection system should be strengthened and designed to prevent the consumption of contaminated products by people. All animals entering the food chain should be subjected to ante-mortem and post-mortem inspection [59].

The primary tool used for screening of bovine tuberculosis is the tuberculin test [60]. The standard control measure applied to tuberculosis is test and slaughter or abattoir surveillance [61]. Screening of meat at slaughterhouses along with detection of slaughtered animal's herd of origin will be helpful in reducing the disease [62]. Tuberculin test is valuable in the control of zoonotic tuberculosis because early recognition of preclinical infection in animals intended for food production and early removal of infected animals from the herd eliminates a future source of infection for other animals and for humans. In the case of cattle, a tuberculin test should be performed in the course of the twelve months prior to presentation for slaughter [63]. There is also need for medical and veterinary professionals should cooperate in cases of disease outbreak [64].

The methods of controlling $M$. bovis in wildlife are limited and dependent on sound disease control principles and judicious use of diagnostic tests. Though population control and vaccination are potential alternative control 
methods but not applicable in all the situations:

- Slaughter of diseased cattle can be an effective policy for tuberculosis eradication, if no other reservoirs of infection are maintained in near surroundings [65].

- In early stage of disease, test and segregation method is followed while in later or terminal stage of disease, test and slaughter method is recommended.

- The animal which is import from other state or country should be strictly quarantine.

- Post mortem examination, meat inspection, intensive surveillance, gamma interferon assay, systematic individual testing of animals, followed by removal of infected and in contact animals for reducing or eliminating the disease [11].

- Ancillary diagnostic techniques, herd testing, health surveillance, ante mortem diagnosis including tuberculin testing and immunization are effective in controlling the TB incidences [52].

- Hygienic measures to prevent the spread of infection should be instituted as soon as the first group of reactors is removed. Feed troughs should be cleaned and thoroughly disinfected with hot, $5 \%$ phenol or equivalent cresol disinfectant. Water troughs and drinking cups should be emptied and similarly disinfected [66].

- Monitoring of the control and eradication programme should be done continuously to know the progress of the programme and for the implementation of necessary modification as required to the programme. Application of advanced genotyping tools and co-operation and co-ordination in human as well as veterinary health care professionals will ultimately help in eradication of bovine tuberculosis especially in developing nation like India [65].

\section{Conclusions}

The spread of tuberculosis from animals to humans in developing countries mostly from infected milk is a serious means of transmission that is being ignored. Milk pasteurization before human consumption is very important, rural dwellers should be educated on the need to boil milk before consumption since they lack infrastructures for pasteurization. Extra pulmonary TB including BTB remains a significant problem in low-income countries and there is a diagnostic challenge in developing countries, where a high rate of HIV infection found.

The disease has an important public health issue due to its zoonotic significance. In certain species of animals, antimicrobial treatment has been attempted but as long term treatment is required so in eradication conscious countries practicing anti-tubercular treatment is not a wise option. Programs involving eradication of the disease consists of inspection of meat at post mortem and conducting surveillance program intensively. This include, on-farm visits, individual testing of cattle systematically along with infected as well as in contact animals' removal and control of movement.

The advances in development of bovine tuberculosis diagnostics and vaccines for cattle are offering valuable insights in the use of vaccination for the control of tuberculosis in a range of bovines and captive wildlife species. The combinations of conventional, immunological and molecular techniques are the best diagnostic tools of TB. But, molecular techniques are limited in developing countries especially in Ethiopia. Thus, Veterinarians and government should have to cooperate to widen the availability and accessibility of these diagnostic techniques as much as possible. In human medicine, vaccination is practiced but as a preventive measure it is not widely used in animals. There is variation in the efficacy of existing vaccines in animals thereby interfering with testing for elimination of the disease. Testing of new candidate vaccines is underway. Combination of BCG vaccine along with vaccine moiety viz., adjuvant subunit and DNA vaccines are more efficacious or superior in providing protection in comparison to BCG alone.

\section{Recommendation}

Based on the above conclusion the following recommendations are forwarded:

- It is important that calves being reared as herd replacements be fed on tuberculosis-free milk, either from known free animals or pasteurized.

- Vaccination against tuberculosis should be supplied for humans and animals as it is zoonotic disease

- Bio-security measures should be followed on herd/farm which helps in decreasing or reducing the interaction between domestic animals and wildlife animals

- Protective cloth should be worn during handling of the diseased animal and infected carcasses.

- Carcasses of infected animals should be buried at least four feet under the ground. 
- The animal which is import from other state or country should be strictly quarantine

- Pasteurisation of milk of before consumption.

- Strict meat inspection should be carried out officially by trained personal

- Treatment of infected animals is not economically feasible because of the high cost, lengthy time and the larger goal of eliminating the disease, so the infected animal should be tested and culled.

- Farm attendants should be checked as they may provide a source of infection.

- Training of personnel at all levels of control programmes and the urgent need for further research on the diagnosis and control, immunological, epidemiological and socioeconomic aspects of the disease.

- Educational and technical assistance should be provided by developed countries to promote control of tuberculosis.

\section{Acknowledgements}

The first gratitude goes to the Almighty God, who is helping me in every sector of my life. In addition, I would like to thanks Jimma University College of Agriculture and Veterinary Medicine internate service that help me in collecting this document. Finally, I would like to thanks my classmates for their active consolidation ideally in my work.

\section{References}

[1] Uduak, A. (2015) A Review on Bovine Tuberculosis. Journal of Veterinary Advances, 5, 841-847.

[2] Theon, C., LoBue, P., Enarson, D., Kaneene, J. and de Kantor, I. (2009) Tuberculosis a Re-Emerging Disease in Animals and Humans. Veterinaria Italiana, 45, 135-181.

[3] Dhama, K., Mahendran, M., Tiwari, R., Singh, S.D., Kumar, D., Singh, S. and Sawant, P.M. (2011) Tuberculosis in Birds: Insights into the Mycobacterium avium Infections. Veterinary Medicine International, 2011, Article ID: 712369. http://dx.doi.org/10.4061/2011/712369

[4] Smith, N.H., Hewinson, R.G., Kremer, K., Brosch, R. and Gordon, S.V. (2009) Myths and Misconceptions: The Origin and Evolution of Mycobacterium tuberculosis. Nature Reviews Microbiology, 7, 537-544. http://dx.doi.org/10.1038/nrmicro2165

[5] Le Roex, N., van Helden, P.D., Koets, A.P. and Hoal, E.G. (2013) Bovine TB in Livestock and Wildlife: What's in the Genes? Physiological Genomics, 45, 631-637. http://dx.doi.org/10.1152/physiolgenomics.00061.2013

[6] Rodriguez-Campos, S., Smith, N.H., Boniotti, M.B. and Aranaz, A. (2014) Overview and Phylogeny of Mycobacterium Tuberculosis Complex Organisms: Implications for Diagnostics and Legislation of Bovine Tuberculosis. Research in Veterinary Science, 97, S5-S19. http://dx.doi.org/10.1016/j.rvsc.2014.02.009

[7] Ereqat, S., Nasereddin, A., Levine, H., Azmi, K. and Al-Jawabreh, A., et al. (2013) First-Time Detection of Mycobacterium bovis in Livestock Tissues and Milk in the West Bank, Palestinian Territories. PLOS Neglected Tropical Diseases, 7. http://dx.doi.org/10.1371/journal.pntd.0002417

[8] Corner, L.A.L. (2006) The Role of Wild Animal Populations in the Epidemiology of Tuberculosis in Domestic Animals: How to Assess the Risk. Veterinary Microbiology, 112, 303-312. http://dx.doi.org/10.1016/j.vetmic.2005.11.015

[9] OIE (2009) Bovine Tuberculosis: Terrestrial Manual. Chapter 2.4.7, 1-16.

[10] Birhanu, T., Mezgebu, E., Ejeta, E., Gizachew, A. and Nekemte, E. (2015) Review on Diagnostic Techniques of Bovine Tuberculosis in Ethiopia. Report and Opinion, 7, 7-14. Marsland Press. http://www.sciencepub.net/report

[11] Verma, A.K., Tiwari, R., Chakraborty, S., Neha, Saminathan, M., Dhama, K. and Singh, S.V. (2014) Insights into Bovine Tuberculosis (bTB), Various Approaches for Its Diagnosis, Control and Its Public Health Concerns: An Update. Asian Journal of Animal and Veterinary Advances, 9, 323-344. http://dx.doi.org/10.3923/ajava.2014.323.344

[12] Shitaye, J.E., Tsegaye, W. and Pavlik, I. (2007) Bovine Tuberculosis Infection in Animal and Human Populations in Ethiopia: A Review. Veterinarni Medicina-Praha-, 52, 317.

[13] Ameni, G., Vordermeier, M., Firdessa, R., Aseffa, A., Hewinson, G., Gordon, S.V. and Berg, S. (2011) Mycobacterium Tuberculosis Infection in Grazing Cattle in Central Ethiopia. Veterinary Journal, 188, 359.

[14] Vial, F., Johnston, W.T. and Donnelly, C.A. (2011) Local Cattle and Badger Populations Affect the Risk of Confirmed Tuberculosis in British Cattle Herds. PloS One, 6. http://dx.doi.org/10.1371/journal.pone.0018058

[15] Graham, J., Smith, G.C., Delahay, R.J., Bailey, T., McDonald, R.A. and Hodgson, D. (2013) Multi-State Modelling Reveals Sex-Dependent Transmission, Progression and Severity of Tuberculosis in Wild Badgers. Epidemiology and Infection, 141, 1429-1436. http://dx.doi.org/10.1017/S0950268812003019 
[16] Biffa, D., Bogale, A., Godfroid, J. and Skjerve, E. (2012) Factors Associated with Severity of Bovine Tuberculosis in Ethiopian Cattle. Tropical Animal Health and Production, 44, 991-998. http://dx.doi.org/10.1007/s11250-011-0031-y

[17] Acevedo, P., Romero, B., Vicente, J., Caracappa, S. and Galluzzo, P. (2013) Tuberculosis Epidemiology in Islands: Insularity, Hosts and Trade. PloS One, 8. http://dx.doi.org/10.1371/journal.pone.0071074

[18] Phillips, C.J.C., Foster, C.R.W., Morris, P.A. and Teverson, R. (2003) The Transmission of Mycobacterium bovis Infection to Cattle. Research in Veterinary Science, 74, 1-15. http://dx.doi.org/10.1016/S0034-5288(02)00145-5

[19] Van Rhijn, I., Godfroid, J., Michel, A. and Rutten, V. (2008) Bovine Tuberculosis as a Model for Human Tuberculosis: Advantages over Small Animal Models. Microbes and Infection, 10, 711-715. http://dx.doi.org/10.1016/j.micinf.2008.04.005

[20] Raviglione, M. and Krech, R. (2011) Tuberculosis: Still a Social Disease. International Journal of Tuberculosis and Lung Disease, 15, S6-S8. http://dx.doi.org/10.5588/ijtld.11.0158

[21] Radostits, O.M., Gay, C.C., Blood, D.C. and Hinchelift, K.W. (2000) Disease Caused by Bacteria-Mycobacterium. In: Radostits, O.M. and Arunde, J.H., Eds., Veterinary Medicine: A Text Book of Disease of Cattle, Sheep, Pig, Goat and Horses, 9th Edition, Harcourt Publisher Ltd., London, 909-918.

[22] Thye, T., Vannberg, F.O., Wong, S.H., Owusu-Dabo, E., Osei, I., et al. (2010) Genome-Wide Association Analyses Identifies a Susceptibility Locus for Tuberculosis on Chromosome 18q11.2. Nature Genetics, 42, 739-741. http://dx.doi.org/10.1038/ng.639

[23] Verhagen, L.M., van den Hof, S., van Deutekom, H., Hermans, P.W., Kremer, K., Borgdorff, M.W. and van Soolingen, D. (2011) Mycobacterial Factors Relevant for Transmission of Tuberculosis. The Journal of Infectious Diseases, 203, 1249-1255. http://dx.doi.org/10.1093/infdis/jir013

[24] Trinkel, M., Cooper, D., Packer, C. and Slotow, R. (2011) Inbreeding Depression Increases Susceptibility to Bovine Tuberculosis in Lions: An Experimental Test Using an Inbred-Outbred Contrast through Translocation. Journal of Wildlife Diseases, 47, 494-500. http://dx.doi.org/10.7589/0090-3558-47.3.494

[25] Perez, F.P. (2012) Contribution to the Epidemiology of Bovine Tuberculosis in Northern Ecuador.

[26] Sharma, S.K., Mohan, A., Sharma, A. and Mitra, D.K. (2005) Miliary Tuberculosis: New Insights into an Old Disease. The Lancet Infectious Diseases, 5, 415-430. http://dx.doi.org/10.1016/S1473-3099(05)70163-8

[27] WHO (2013) Global Tuberculosis Control: Epidemiology, Strategy and Financing. WHO, Geneva, 1-341.

[28] Patterson, J. and Grooms, D. (2000) Diagnosis of Bovine Tuberculosis: Gross Necropsy, Histopathology and Acid Fast Staining. Michigan State University Extension, 35, 1-2.

[29] Cousins, D.V. (2001) Mycobacterium bovis Infection and Control in Domestic Livestock. Scientific and Technical Review of the Office International des Epizooties, 20, 71-85.

[30] Chambers, M.A. (2013) Review of the Diagnosis of Tuberculosis in Non-Bovid Wildlife Species Using Immunological Methods-An Update of Published Work since 2009. Transboundary Emerging Disease, 60, 14-27. http://dx.doi.org/10.1111/tbed.12094

[31] Lyashchenko, K., Whelan, A.O., Greenwald, R., Pollock, J.M., Andersen, P., Hewinson, R.G. and Vordermeier, H.M. (2004) Association of Tuberculin-Boosted Antibody Responses with Pathology and Cell-Mediated Immunity in Cattle Vaccinated with Mycobacterium bovis BCG and Infected with M. bovis. Infection and Immunity, 72, 2462-2467. http://dx.doi.org/10.1128/IAI.72.5.2462-2467.2004

[32] Gan, W., Zhou, X., Yang, H., Chen, H., Qiao, J., et al. (2013) Development of a Test for Bovine Tuberculosis in Cattle Based on Measurement of Gamma Interferon mRNA by Real-Time PCR. Veterinary Record, 173, 117. http://dx.doi.org/10.1136/vr.101552

[33] Parlane, N.A. and Buddle, B.M. (2015) Immunity and Vaccination against Tuberculosis in Cattle. Current Clinical Microbiology Reports, 2, 44-53. http://dx.doi.org/10.1007/s40588-014-0009-4

[34] Ameni, G., Vordermeier, M., Aseffa, A., Young, D.B. and Hewinson, R.G. (2010) Field Evaluation of the Efficacy of Mycobacterium bovis Bacillus Calmette-Guerin against Bovine Tuberculosis in Neonatal Calves in Ethiopia. Clinical and Vaccine Immunology, 17, 1533-1538. http://dx.doi.org/10.1128/CVI.00222-10

[35] Tessema, B., Beer, J., Emmrich, F., Sack, U. and Rodloff, A.C. (2012) First and Second Line Anti-Tuberculosis Drug Resistance in Northwest Ethiopia. International Journal of Tuberculosis and Lung Disease, 16, 805-811. http://dx.doi.org/10.5588/ijtld.11.0522

[36] Biadglegne, F., Tessema, B., Rodloff, A.C. and Sack, U. (2013) Magnitude of Gene Mutations Conferring Drug Resistance in Mycobacterium Tuberculosis Isolates from Lymph Node Aspirates in Ethiopia. International Journal of Medical Sciences, 10, 1589-1594. http://dx.doi.org/10.7150/ijms.6806

[37] Esmael, A., Ali, I., Agonafir, M., Endris, M., Getahun, M., Yaregal, Z. and Desta, K. (2014) Drug Resistance Pattern of M. tuberculosis in Eastern Amhara Regional State, Ethiopia. Journal of Microbial \& Biochemical Technology, 6, 
075-079.

[38] Hirpa, S., Medhin, G., Girma, B., Melese, M. and Mekonen, A. (2013) Determinants of Multidrug-Resistant Tuberculosis in Patients Who Underwent First-Line Treatment in Addis Ababa: A Case Control Study. BMC Public Health, 13, 782. http://dx.doi.org/10.1186/1471-2458-13-782

[39] Mekonnen, F., Tessema, B., Moges, F., Gelaw, A., Eshetie, S. and Kumera, G. (2015) Multidrug Resistant Tuberculosis: Prevalence and Risk Factors in Districts of Metema and West Armachiho, Northwest Ethiopia. BMC Infectious Diseases, 15, 461. http://dx.doi.org/10.1186/s12879-015-1202-7

[40] Biadglegne, F., Sack, U. and Rodloff, A.C. (2014) Multidrug-Resistant Tuberculosis in Ethiopia: Efforts to Expand Diagnostic Services, Treatment and Care. Antimicrobial Resistance and Infection Control, 3, 31. http://dx.doi.org/10.1186/2047-2994-3-31

[41] Federal Ministry of Health of Ethiopia (2009) Guideline for Program and Clinical Management of Drug Resistant Tuberculosis. FMOH, Addis Ababa, 5.

[42] World Health Organization (2013) WHO Report 2013. Global Tuberculosis Control. World Health Organization, Geneva. http://www.who.int/tb/data

[43] Biadglegne, F., Tesfaye, W., Anagaw, B., Tessema, B, Debebe, T., Anagaw, B., Mulu, A., Sack, U. and Rodloff, A.C. (2013) Tuberculosis Lymphadenitis in Ethiopia. Japanese Journal of Infectious Diseases, 66, 263-268. http://dx.doi.org/10.7883/yoken.66.263

[44] Joardar, S.N., Ram, G.C. and Goswami, T.K. (2003) Mycobacterium bovis AN5 Antigens Vary in Their Ability to Induce Nitric Oxide Production in Blood Monocytes of Experimentally Infected Cattle. Veterinary Immunology and Immunopathology, 93, 61-68. http://dx.doi.org/10.1016/S0165-2427(03)00053-9

[45] O’Reilly, L.M. and Daborn, C.J. (1995) The Epidemiology of Mycobacterium bovis Infections in Animals and Man: A Review. Tubercle and Lung Disease, 76, 1-46. http://dx.doi.org/10.1016/0962-8479(95)90591-X

[46] Rodriguez-Campos, S., Smith, N.H., Boniotti, M.B. and Aranaz, A. (2014) Overview and Phylogeny of Mycobacterium tuberculosis Complex Organisms: Implications for Diagnostics and Legislation of Bovine Tuberculosis. Research in Veterinary Science, 97, S5-S19. http://dx.doi.org/10.1016/j.rvsc.2014.02.009

[47] Perez-Lago, L., Navarro, Y. and Garcia-de-Viedma, D. (2013) Current Knowledge and Pending Challenges in Zoonosis Caused by Mycobacterium bovis: A Review. Research in Veterinary Science, 97, S94-S100. http://dx.doi.org/10.1016/j.rvsc.2013.11.008

[48] Malama, S., Muma, J.B. and Godfroid, J. (2013) A Review of Tuberculosis at the Wildlife-Livestock-Human Interface in Zambia. Infectious Diseases of Poverty, 2, 13. http://dx.doi.org/10.1186/2049-9957-2-13

[49] Etter, E., Donado, P., Jori, F., Caron, A., Goutard, F. and Roger, F. (2006) Risk Analysis and Bovine Tuberculosis, a Re-Emerging Zoonosis. Annals of the New York Academy of Sciences, 1081, 61-73. http://dx.doi.org/10.1196/annals.1373.006

[50] Evans, J.T., Smith, E.G., Banerjee, A., Smith, R.M.M., Dale, J., et al. (2007) Cluster of Human Tuberculosis Caused by Mycobacterium bovis: Evidence for Person-to-Person Transmission in the UK. Lancet, 369, 1270-1276. http://dx.doi.org/10.1016/S0140-6736(07)60598-4

[51] Asseged, B., Woldesenbet, Z., Yimer, E. and Lemma, E. (2004) Evaluation of Abattoir Inspection for the Diagnosis of Mycobacterium bovis Infection in Cattle at Addis Ababa Abattoir. Tropical Animal Health and Production, 36, 537-546. http://dx.doi.org/10.1023/B:TROP.0000040934.32330.44

[52] Torgerson, P.R. and Torgerson, D.J. (2010) Public Health and Bovine Tuberculosis: What's All the Fuss about? Trends in Microbiology, 18, 67-72. http://dx.doi.org/10.1016/j.tim.2009.11.002

[53] Atkinson, S., Valadas, E., Smith, S.M., Lukey, P.T. and Dockrell, H.M. (2000) Monocyte-Derived Macrophage Cytokine Responses Induced by M. bovis BCG. Tubercle and Lung Disease, 80, 197-207.

http://dx.doi.org/10.1054/tuld.2000.0247

[54] Vento, S. and Lanzafame, M. (2011) Tuberculosis and Cancer: A Complex and Dangerous Liaison. The Lancet Oncology, 12, 520-522. http://dx.doi.org/10.1016/S1470-2045(11)70105-X

[55] Cosivi, O., Grange, J.M., Daborn, C.J., Raviglione, M.C., Fujikura, T., Cousins, D., Robinson, R.A., Huchzermeyer, H.F., de Kantor, I. and Meslin, F.X. (1998) Zoonotic Tuberculosis Due to Mycobacterium bovis in Developing Countries. Emerging Infectious Diseases, 4, 1-17. http://dx.doi.org/10.3201/eid0401.980108

[56] Theon, C., Lobue, P., Enarson, D., Kaneene, J. and de Kantor, I. (2009) Tuberculosis a Re-Emerging Disease in Animals and Humans. Veterinaria Italiana, 45, 135-181.

[57] Krauss, H., Weber, A., Appel, M., Enders, B., Isenberg, D.H., Schiefer, G.H., Slenczka, W., von Graevenitz, A. and Zahner, H. (2003) Zoonoses: Infectious Diseases Transmissible from Animals to Humans. Third Edition, ASM Press, Washington DC, 213. http://dx.doi.org/10.1128/9781555817787 
[58] Pavlik, I., Ayele, W.Y., Parmova, I., Melicharek, I., Hanzlikova, M., Körmendy, B., Nagy, G., Cvetnic, Z., Ocepek, M., Fejzic, N. and Lipiec, M. (2002) Incidence of Bovine Tuberculosis in Cattle in Seven Central European Countries during the Years 1990-1999. Veterinarni Medicina, 47, 45-51.

[59] Nwanta, J.A., Onunkwo, J.I., Ezema, W.S. and Umeononigwe, C.N. (2010) Zoonotic Tuberculosis: A Review of Epidemiology, Clinical Presentation, Prevention and Control. Journal of Public Health and Epidemiology, 2, 118-124.

[60] Schiller, I., Ray Waters, W., Vordermeier, H.M., Jemmi, T., Welsh, M., et al. (2011) Bovine Tuberculosis in Europe from the Perspective of an Officially Tuberculosis Free Country: Trade, Surveillance and Diagnostics. Veterinary Microbiology, 151, 153-159. http://dx.doi.org/10.1016/j.vetmic.2011.02.039

[61] Schiller, I., Vordermeier, H.M., Waters, W.R., Whelan, A.O., Coad, M., et al. (2010) Bovine Tuberculosis: Effect of the Tuberculin Skin Test on in Vitro Interferon Gamma Responses. Veterinary Immunology and Immunopathology, 136, 1-11. http://dx.doi.org/10.1016/j.vetimm.2010.02.007

[62] Smith, R.L., Tauer, L.W., Sanderson, M.W. and Grohn, Y.T. (2014) Minimum Cost to Control Bovine Tuberculosis in Cow-Calf Herds. Preventive Veterinary Medicine, 115, 18-28. http://dx.doi.org/10.1016/j.prevetmed.2014.03.014

[63] Food Safety Authority of Ireland (FSAI) (2008) Zoonotic Tuberculosis and Food Safety. 2nd Edition, Food Safety Authority of Ireland, Abbey Court, Dublin, 1-28.

[64] Kahn, L.H., Kaplan, B. and Steele, J.H. (2007) Confronting Zoonosis through Collaboration between Medicine and Veterinary Medicine (as “One Medicine”). Veterinaria Italiana, 43, 5-19.

[65] Verma, A.K., Dhama, K., Chakraborty, S., Kumar, A., Tiwari, R., et al. (2014) Strategies for Combating and Eradicating Important Infectious Diseases of Animals with Particular Reference to India: Present and Future Perspectives. Asian Journal of Animal and Veterinary Advances, 9, 77-106. http://dx.doi.org/10.3923/ajava.2014.77.106

[66] Woolhouse, M.E., Dye, C., Etard, J.F., Smith, T., Charlwood, J.D., et al. (1997) Heterogeneities in the Transmission of Infectious Agents: Implications for the Design of Control Programs. Proceedings of the National Academy of Sciences of the United States of America, 94, 338-342. http://dx.doi.org/10.1073/pnas.94.1.338

\section{Abbreviations}

AFB: Acid Fast Bacilli;

BCG: Bacillus of Calmette and Guerin;

BTB: Bovine Tuberculosis;

DOTS: Directly Observed Therapy, Short Course;

ELISA: Enzyme Linked Immune Sorbent Assay;

MDR: Multidrug Resistant;

MTC: Mycobacterium Tuberculosis Complex;

MDR-TB: Multidrug Resistant Tuberculosis;

PCR: Polymerase Chain Reaction;

PPD: Purified Protein Derivative;

RT-QPCR: Real Time Quantitative PCR;

TB: Tuberculosis;

TDR: Totally Drug Resistant;

XDR: Extremely Drug Resistant;

ZN: Ziehl-Neelsen. 